\title{
Compras públicas: uma revisão sistemática dos riscos e desafios
}

\section{Public purchases: a systematic review of challenges and opportunities}

\author{
Robinson Alexander Sturmer ${ }^{1}$, Elias Garcia ${ }^{2}$, Eliane Nascimento Pereira ${ }^{3}$, Fabiana Frata Furlan Peres ${ }^{4}$ \\ 1 Universidade Estadual do Oeste do Paraná (UNIOESTE), Foz do Iguaçu, Paraná, Brasil. ORCID: https://orcid.org/0000-0002-3373-1526 \\ 2 Universidade Estadual do Oeste do Paraná (UNIOESTE), Foz do Iguaçu, Paraná, Brasil. ORCID: https://orcid.org/0000-0001-9332-2532 \\ ${ }^{3}$ Universidade Estadual do Oeste do Paraná (UNIOESTE), Foz do Iguaçu, Paraná, Brasil. ORCID: https://orcid.org/0000-0003-4285-3215 \\ ${ }^{4}$ Universidade Estadual do Oeste do Paraná (UNIOESTE), Foz do Iguaçu, Paraná, Brasil. ORCID: https://orcid.org/0000-0002-3937-3432
}

Autor para correspondência/Mail to: Robinson Alexander Sturmer, robinson.sturmer@unila.edu.br

Recebido/Submitted: 06 de março de 2021; Aceito/Approved: 02 de junho de 2021

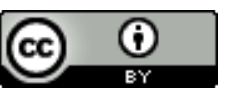
Copyright (c) 2022 Sturmer, Garcia, Pereira \& Peres. Todo o conteúdo da Revista (incluindo-se instruções, política editorial e modelos) está sob uma licença Cre-
ative Commons Atribuição 4.0 Internacional. Ao serem publicados por esta Revista, os artigos são de livre uso em ambientes educacionais, de pesquisa e não
comerciais, com atribuição de autoria obrigatória. Mais informações em http://revistas.ufpr.br/atoz/about/submissions\#copyrightNotice.

\begin{abstract}
Resumo
Introdução: As compras públicas consistem em um importante mecanismo que leva as políticas públicas a efeito, representam grande parte dos gastos da Administração e pressionam os gestores a buscar maior governança dos gastos públicos. Assim, este artigo faz uma breve exposição dos riscos e desafios relacionados às compras públicas; Método: Consiste em revisão sistemática da literatura e análise qualitativa dos resultados em duas etapas: uma com foco na análise dos dados coletados e a outra nos aspectos relacionados aos riscos e desafios que se apresentam nas pesquisas. Resultados: Foram identificados 272 artigos, dos quais 36 foram selecionados para a extração de dados. Temas como governança, sustentabilidade, governo eletrônico, desenvolvimento local e sustentabilidade estão em destaque nas pesquisas. Conclusão: os desafios que se impõem aos operadores das compras públicas são diversos, destacando-se fatores como legislação confusa, falta de planejamento, de conhecimento e de sinergia por parte dos responsáveis, fatores que podem reduzir os resultados ou frustrar a aquisição. A utilização de sistemas eletrônicos, associada ao treinamento e envolvimento dos gestores de compras pode ser uma importante ferramenta para fomentar o planejamento, reduzir riscos relativos aos desvios de finalidades e superar os desafios que se observam nas compras públicas, abrindo campo para que estas possam ser utilizadas como instrumento de implementação de políticas econômicas, sustentáveis e de desenvolvimento em sua plenitude.
\end{abstract}

Palavras-chave: Compras públicas; Governança; Gestão de riscos; Sustentabilidade.

\begin{abstract}
Introduction: Public procurement is an important mechanism that takes public policies into effect, represents a large part of the Administration's expenses and puts pressure on managers to seek more governance of public expenditures. Thus, this article briefly exposes the risks and challenges related to public procurement; Method: It consists of a systematic review of the literature and qualitative analysis of the results in two stages: one focusing on the analysis of the collected data and the other on aspects related to the risks and challenges presented in the research. Results: It identifies 272 articles, of which it selects 36 for data extraction. It highlights the themes: governance, sustainability, e-government, local development and sustainability. Conclusion: the challenges facing public procurement operators are diverse, highlighting factors such as confusing legislation, lack of planning, knowledge and synergy by those responsible, factors that can reduce results or frustrate the acquisition. The use of electronic systems, associated with the training and involvement of purchasing managers, can be an important tool to promote planning, reduce risks related to deviations in purposes and overcome the challenges that are observed in public procurement, opening up the field so that they can be an instrument for the implementation of economic, sustainable and development policies in full.
\end{abstract}

Keywords: Public purchases; Governance; Risk management; Sustainability.

\section{INTRODUÇÃO}

Observamos com frequência várias notícias nos jornais sobre aquisição de equipamentos hospitalares, respiradores, máscaras, remédios, oxigênio, compra de vacinas e outros tipos de bens e materiais de uso contínuo para que as intuições públicas possam prestar seus serviços à população. Todas essas aquisições são demandadas por autoridades públicas e operacionalizadas pela área de compras das instituições, nas quais operam servidores públicos selecionados para tal atividade, que doravante denominamos compra pública.

Nas palavras de Oliveira (2015), as compras públicas consistem em aquisições de bens e serviços para prover demandas de cumprimento das funções do Estado, tais como saúde, educação e segurança, e representam grande parte dos gastos da Administração Pública.

Tal como ocorre no setor privado, a rotina das aquisições em instituições públicas está permanentemente exposta a desafios, que por sua vez são permeados por riscos que podem reduzir a capacidade institucional de gerar resultados e benefícios para a sociedade. A aquisição de vacinas para a COVID-19 é um exemplo latente e atual destes desafios, pois mesmo que os gestores públicos empreendam esforços para efetivamente prover o quantitativo necessário de vacinas para toda a população, fatores alheios à vontade de quem opera esta aquisição 
impacta e até frustra a compra. Ocorre que alguns destes fatores podem ser previamente identificados e assim receber um tratamento para que os seus resultados negativos sejam anulados ou reduzidos.

A literatura consultada aponta que os governos têm aplicado significativos esforços para aumentar a eficiência e eficácia desta função chave do Estado, pois busca maior governança dos gastos públicos. Assim sendo, este artigo faz uma breve exposição de conceitos relacionados às compras públicas, governança, gerenciamento de riscos e sustentabilidade utilizando a metodologia de revisão sistemática. Os resultados são divididos em duas etapas: uma com foco na análise dos dados coletados e a outra nos aspectos relacionados aos riscos e desafios que se apresentam nas pesquisas.

Ao final do artigo, elaboramos um apanhado geral dos resultados, no qual se pode verificar a importância das compras na economia, na inovação, na qualidade de vida, na política e no desenvolvimento sustentável, evidenciando a necessidade da valorização da área de gestão de riscos das compras para que as instituições públicas ampliem seu potencial de gerar valor para a sociedade em geral.

\section{PROCEDIMENTOS METODOLÓGICOS}

Segundo Denyer e Tranfield (2009), a revisão sistemática é uma metodologia específica que busca localizar os estudos existentes na área de pesquisa, selecionando, avaliando suas contribuições, analisando e sintetizando dados, e divulgando as evidências de forma que seja possível identificar o conhecimento sobre a área de pesquisa.

Quanto aos procedimentos técnicos, utilizou-se de pesquisa bibliográfica, que envolveu a análise dos dados extraídos dos artigos científicos, com destaque às características investigadas. Em relação aos dados, foram coletados a partir de delimitações formuladas no protocolo de Revisão Sistemática da Literatura - RSL com objetivo de analisar as compras públicas sob a perspectiva dos riscos e desafios a elas relacionadas, visando gerar conhecimento sobre os estudos realizados e eventuais lacunas que demandam investigação, propondo uma pauta para avanço nessa área. A RSL utilizou-se de uma pesquisa de natureza qualitativa e descritiva para análise dos dados.

Para o processo de seleção, reflexão e análise do fragmento da literatura, utilizou-se de consulta às bases de dados disponíveis no Portal de Periódicos da Capes, com base no eixo de pesquisa selecionado. Foram definidas como fonte de dados para consulta as bases de dados indexadas da Web of Science (Elsevier), Scopus e Spell, devido à sua correspondência com a produção científica na área da Administração Pública. A coleta de dados foi realizada no dia 02 de setembro de 2020, na qual se utilizou a string de busca com o seguinte formato: ("COMPRA PUBLICA" OR "AQUISIÇÃO PÚBLICA"OR "COMPRA GOVERNAMENTAL"OR "PUBLIC ACQUISITION"OR "PUBLIC PROCUREMENT"OR "PUBLIC PURCHASES"OR "PUBLIC $\left.P U R C H A S I N G^{\prime \prime}\right)$, resultando em 5.270 produções correlatas.

Estes resultados foram filtrados nas bases e limitados a estudos com acesso livre, revisados por pares, de idioma português, inglês ou espanhol, assim como, somente aqueles que estivessem dentro das seguintes áreas: Business, Management and Accounting; Economics, Econometrics and Finance; Multidisciplinary e Public Administration. Como resultado, retornaram 272 referências que foram convertidas em arquivos no formato Bibtex e importados para o Parsifal, ferramenta on-line desenvolvida para apoiar pesquisadores na realização de RSL, documentando a fase de planejamento e fornecendo suporte para a busca dos objetivos, como campos correlatos as questões de pesquisa, string de busca, palavras-chave e sinônimos, fontes, e critérios de inclusão e exclusão, além de mecanismos para verificação de avaliação de qualidade e formulários de extração de dados.

Com o auxílio do Parsifal, foram examinados título e abstract dos artigos, e excluídos aqueles claramente desalinhados e que, na percepção dos pesquisadores, não contribuiriam para o desenvolvimento da pesquisa. Referências duplicadas também foram excluídas, restando 123 artigos para análise. Um dado interessante a ser explorado é a tempestividade dos estudos selecionados, pois como demonstra a Figura ??, a partir de 2014 o tema passou a ser explorado com maior frequência, com o pico quantitativo em 2019. Considerando que as buscas foram realizadas no mês de setembro de 2020, pode-se afirmar que há tendência de aumento nas produções científicas em 2020. 


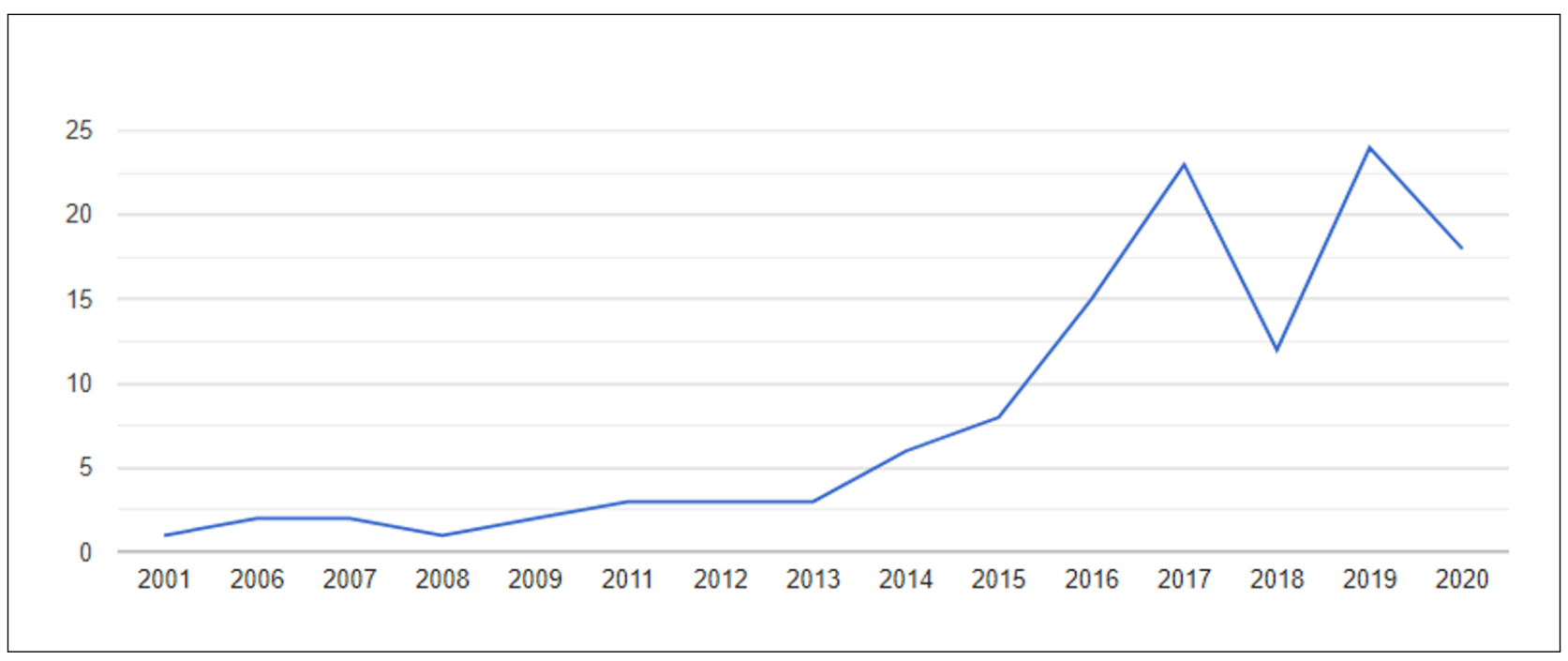

Figura 1. Tempestividade dos estudos.

Com os artigos pré-selecionados, seguiu-se para a avaliação de qualidade com a leitura da introdução e conclusão dos artigos, pontuando e classificando cada um de acordo com o questionário de avaliação elaborado pelos autores (Tabela 1). Aqueles com notas abaixo de 3,5 foram desconsiderados para a extração de dados.

\begin{tabular}{|c|c|c|c|c|}
\hline \multicolumn{5}{|c|}{ Questionário para avaliação de qualidade (fase 3) NOTA DE COR7 } \\
\hline $\begin{array}{l}\text { O artigo trata de desafios ou riscos relacionados as com- } \\
\text { pras públicas? }\end{array}$ & $\operatorname{Sim}(1,00)$ & Parcial $(0,6)$ & Pouco $(0,3)$ & Não $(-0,1)$ \\
\hline Compras como instrumento de política pública? & $\operatorname{Sim}(1,00)$ & Parcial $(0,6)$ & Pouco $(0,3)$ & Não $(-0,1)$ \\
\hline Compras inteligentes como impulso para inovação? & $\operatorname{Sim}(1,00)$ & Parcial $(0,6)$ & Pouco $(0,3)$ & Não $(-0,1)$ \\
\hline Compras sustentáveis? & $\operatorname{Sim}(1,00)$ & Parcial $(0,6)$ & Pouco $(0,3)$ & Não $(-0,1)$ \\
\hline O artigo trata de compras públicas? & $\operatorname{Sim}(1,00)$ & Parcial $(0,6)$ & Pouco $(0,3)$ & Não $(-0,1)$ \\
\hline O artigo trata de Governança? & $\operatorname{Sim}(1,00)$ & Parcial $(0,6)$ & Pouco $(0,3)$ & Não $(-0,1)$ \\
\hline O artigo trata de compras públicas no contexto brasileiro? & $\operatorname{Sim}(1,00)$ & Parcial $(0,6)$ & Pouco $(0,3)$ & Não $(-0,1)$ \\
\hline O artigo trata de gestão de riscos? & $\operatorname{Sim}(1,00)$ & Parcial $(0,6)$ & Pouco $(0,3)$ & Não $(-0,1)$ \\
\hline $\begin{array}{l}\text { O artigo faz alguma relação entre os impactos da gestão } \\
\text { dos riscos nas compras públicas na governança das insti- } \\
\text { tuições? }\end{array}$ & $\operatorname{Sim}(1,00)$ & Parcial $(0,6)$ & Pouco $(0,3)$ & Não $(-0,1)$ \\
\hline Pontuação máxima & 9 & & & \\
\hline
\end{tabular}

Tabela 1. Questionário de avaliação.

Finalizada a etapa de seleção, o processo de RSL resultou num total de 34 (trinta e quatro) artigos para extração de dados. A análise foi elaborada com o apoio da ferramenta Mendeley, para melhor organização do conteúdo pois oferece a sistematização dos dados relativos aos direitos autorais e endereço para localização do arquivo na internet, além de auxiliar a leitura dos documentos PDF, com opções como anotações e grifos. A busca por termos dentro do aplicativo também é de grande relevância quando se trata de RSL, e ajudaram a buscar informações acerca das seguintes perguntas, norteadoras desta pesquisa: Quais os riscos e desafios relacionados às compras públicas? Quais os resultados da pesquisa?

\section{ANÁLISE DOS RESULTADOS}

A condução da RSL revelou diversos aspectos que se relacionam às compras públicas, e embora a gestão de risco não seja objeto direto dos artigos selecionados, este aspecto está presente quando se abordam os desafios. Segundo o PMI (2017), risco "é um evento ou condição incerta que, se ocorrer, provocará um efeito positivo ou negativo em um ou mais objetivos do projeto"(p. 677) tais como escopo, cronograma, custo e qualidade.

A pesquisa apontou para um conjunto de 34 artigos, dos quais 26 (vinte seis) ou $76 \%$ versam sobre temas relacionados ao Brasil, revelando a preocupação da comunidade acadêmica nacional quanto ao tema compras públicas. Outros oito artigos abordam o panorama internacional, cuja temática traz dados da Croácia, Letônia, País de Gales, Itália, Lituânia e Zimbábue, incorporando uma diversidade interessante a esta pesquisa, uma vez que são países com realidades sociais e econômicas distintas, mas com problemáticas semelhantes, denotando que o tema ora abordado não está restrito a países pobres, ricos ou subdesenvolvidos. Os desafios e as medidas para mitigar os riscos observados nos artigos podem fornecer indicativos de como atacar estes problemas em qualquer país, concorrendo para o melhor aproveitamento e disseminação de boas experiências e práticas já implantadas. 
Quanto aos procedimentos de extração de dados, considerando a necessidade de categorizar e organizar as informações coletadas para a análise, observamos os seguintes aspectos do protocolo da RSL: local do estudo, tema e foco, objetivo e principal resultado.

Na sequência os artigos foram segmentados e agrupados em categorias para análise Bardin (2016). Entre os temas observados nos estudos, as Compras para Inovação focaram no incentivo ao desenvolvimento de tecnologia local, na capacidade de inovação das empresas como meio de desenvolvimento econômico e no uso do poder de compra como instrumento de incentivo às inovações. Outra vertente abordou o Desenvolvimento local, com estudos voltados às micro e pequenas empresas e à agricultura familiar, enquanto sob o tema Sustentabilidade os autores enfatizaram o papel e os critérios de sustentabilidade; com a centralização ou compartilhamento de compras sustentáveis e com a percepção dos agentes envolvidos nas compras. Com importante destaque nos estudos, o tema Governança abarcou a centralização de compras, estruturação organizacional, eficiência, eficácia, avaliação de desempenho dos processos, implantação de sistemas gerenciais, governo eletrônico, planejamento e Gestão de riscos.

É importante registrar que estas categorias e conclusões não têm como objetivo segregar determinado tema de estudo como um risco ou desafio, uma vez que tal condição é inerente a qualquer situação incerta ou problema que possa surgir. Dito isso, todas as categorias têm seus desafios e podem ser permeadas por uma situação incerta ou um grande problema a ser vencido ou superado, e desta forma guardam direta relação com a governança e o sucesso das compras públicas. Na próxima seção, faremos um resumo contendo as principais conclusões dos autores acerca do papel que estes temas representam para as compras públicas.

\section{Compras para inovação}

Ao tratar do tema inovação, o governo dos países em desenvolvimento tem utilizado de seu arsenal de políticas industriais e tecnológicas para estimular as empresas locais a participar de encomendas governamentais com vistas a acumularem níveis inovadores. Ribeiro e Furtado (2015) relataram obstáculos como a falta de capacitação tecnológica das empresas, que ainda impedem o desenvolvimento da indústria e concluem que, mesmo adotando uma política de compras indutora, ainda se observa a dependência tecnológica estrangeria no país.

Moreira e Vargas (2015) asseveram que, quando contratadas para prestar serviços de software para o Governo Federal, as empresas acabam inovando, mas estas inovações (desenvolvidas para clientes governamentais) podem não ser inteiramente reaproveitadas por clientes e indica a não correspondência à premissa original das compras públicas, que preveem o desenvolvimento de inovações capazes de serem difundidas na economia. Para que se possa utilizar as compras para a inovação é necessário que se estabeleçam requisitos para aquisição de bens ou serviços ainda inexistentes no mercado, mas com potencial para serem desenvolvidos e posteriormente utilizados pelo mercado consumidor.

Evidências da utilização das compras como incentivo à inovação por parte de fornecedores também são descritas por Camargos e Moreira (2015), pois afirmam que a inovação faz parte do discurso dos servidores e certamente tem sua simpatia, mas não se converte em compras efetivas para a inovação, pois estes querem inovações, mas não sabem, efetivamente, o que contratar.

\section{As compras e o desenvolvimento local}

As Compras públicas também podem ser indutores do desenvolvimento local, visto que agregam valor às empresas e comunidades ao torná-las fornecedoras do Estado. Caldas e Nonato (2013) apresentam as compras públicas governamentais como ferramenta estratégica de apoio ao desenvolvimento local e trazem a experiência da cidade de Apucarana/PR. Os autores demonstram que os Municípios são capazes de criar políticas públicas para resolverem seus problemas e ainda promover o desenvolvimento local por meio das compras públicas. No estudo, observaram que os gestores de políticas públicas locais superaram desafios ao empreender esforços na confecção de leis, articulação com os produtores locais, logística, recepção e distribuição dos produtos a serem consumidos, incentivando o desenvolvimento econômico local.

O mesmo movimento deveria ser observado quando pensamos nas pequenas e médias empresas - PMEs, que inclusive gozam de legislação que as privilegia justamente para que possam agregar valor às suas comunidades. Cabral, Reis, e Sampaio (2015) observaram os condicionantes da participação e do sucesso de Micro e Pequenas Empresas (MPE) em compras públicas a partir de alterações na legislação. Os autores registram que a documentação, o tempo e o custo envolvidos na preparação das propostas estão entre as principais barreiras para a participação nas contratações governamentais. As análises demonstraram que fatores como divisão de contratos e mudanças institucionais, promovidas pela Lei Geral das MPE, contribuíram significativamente para o aumento na participação de MPE nos processos de licitações por meio de pregão eletrônico, porém não alteraram a probabilidade de êxito de empresas de pequeno porte em certames públicos, colocando em perspectiva a eficácia da legislação implantada.

Conclusão similar é registrada por Chaves, Bertassi, e Silva (2018), pois concluem que existem dificuldades na utilização da licitação como instrumento de política pública, apontando que é preciso avançar muito na 
discussão acerca da utilização do poder de compra do Estado como potencial indutor de desenvolvimento regional. Corrobora neste sentido o estudo de Rocha (2019), indicando que a política de inovação e desenvolvimento brasileira tem problemas em atingir as pequenas e médias empresas, pois visa principalmente as de grande porte, que já são inovadoras e tem alto desempenho em P\&D.

\section{Sustentabilidade nas compras}

Silva e Barki (2012), ao apresentarem as compras compartilhadas de itens e de materiais de expediente ambientalmente corretos, afirmam que há possibilidade de implantar um sistema de aquisições públicas voltadas à sustentabilidade que podem impulsionar o desenvolvimento. Esta situação, apesar dos grandes desafios encontrados (inexperiência dos órgãos com compras sustentáveis e períodos de compras incompatíveis), destaca como diferencial do a motivação apresentada pelos membros, mas cita os riscos em relação ao uso excessivo e exclusivo dos instrumentos de comando e controle, em conjunto com a multiplicidade e conflito dos diversos atores envolvidos na formulação de políticas ambientais, como um fator que contribui para a pouca agilidade, altos custos transacionais e para o comportamento resistente a mudanças. Por fim, os autores demonstraram que a utilização do Pregão SRP compartilhado possibilita a realização de compras ambientalmente corretas e economicamente eficientes para todos os participantes.

O estudo de Hall, de Moura, Macêdo, e da Cunha (2014) revela uma heterogeneidade nos aspectos relativos às compras sustentáveis das universidades. Muitas apresentaram a informação de que não estavam aplicando ou aplicavam de forma parcial os aspectos sobre as questões ambientais. Quanto aos produtos, as universidades, na sua maioria, buscavam adquirir produtos de qualidade e com uma durabilidade maior, além de buscar produtos com menor consumo de água e energia.

Do mesmo modo, Ferreira Costa, Diniz, Cunha, e Pires (2016) revelaram que, na prática, a Administração não está preparada para realizar procedimentos licitatórios sustentáveis em razão da sua deficiência em identificar, na fase de planejamento, o impacto ambiental do objeto a ser executado e acaba por deixar de exigir no edital de licitação os requisitos para conservação e proteção do meio ambiente, necessários para o cumprimento do objeto com respeito às normas ambientais. É notável, de acordo com os estudos, a necessidade de treinamento e qualificação dos atores envolvidos nas aquisições, pois o desconhecimento do conceito e dos critérios de sustentabilidade aplicados a prática das compras públicas, é fator decisivo para que tal objetivo possa ser alçado a outro nível.

Todavia, Mendonça, Cruz, Teodosio, e Raso (2017) relatam que este sucesso só pode ser alcançado se houver a predominância do pilar regulatório, que tem como base de legitimação as normas legalmente postas, entendendo ser mais fácil adotar uma estrutura de organização por lei ou decreto, do que institucionalizar o correspondente comportamento social. Ao final do estudo, relatam que após a implantação deste modelo, é necessário um contínuo esforço das instituições públicas para que as normativas legais estejam sempre atualizadas aos constantes desafios do Estado, e que o planejamento para a implementação e manutenção destes mecanismos legais abarque não somente os chefes dos poderes, mas que busquem uma governança colaborativa, com envolvimento e engajamento de todos aqueles que direta ou indiretamente são responsáveis pelas aquisições públicas.

Este foco foi relatado por Rosset e Finger (2017), que apontam o Pregão Eletrônico como um grande avanço nas compras públicas sustentáveis, pois foram valoradas as categorias transparência, eficiência e economia e defendem a simplificação dos processos de compra, mas ainda caracterizam o sistema atual como moroso.

Esta morosidade pode estar relacionada também a outros fatores, como os normativos legais e humanos, pois outros autores defendem diferentes posições neste sentido. Um exemplo é o que G. C. d. Araújo e Teixeira (2018) concluíram ao afirmar que não há profissionalização das compras públicas sustentáveis, não existe uma padronização e nem mesmo estudos aprofundados que comprovem a efetiva contribuição socioambiental dessas compras, tais como ciclo de vida dos produtos. Os autores registram que os responsáveis pelas compras públicas decidem os critérios sustentáveis de forma intuitiva e que nem sempre contribuem com fatores socioambientais positivos que deveriam. Sousa e Carvalho (2018) defendem a necessidade de qualificação dos servidores responsáveis pelas compras, devido ao desconhecimento das normas e dos próprios critérios ambientais, além da inadequação do mercado fornecedor, fator que dificulta a inserção dos critérios ambientais nos editais e concluem que as licitações estudadas não cumprem a finalidade legal de promover o desenvolvimento sustentável, nem a função social, pela errônea interpretação do princípio da economicidade - desconsiderando o valor de uso dos bens e serviços e negligenciando os critérios ambientais.

Em situação oposta Cader da Silva, Betiol, Villac, e Nonato (2018) relatam a exitosa experiência das compras públicas sustentáveis por meio de aquisições compartilhadas. Os autores fundamentam o sucesso no Planejamento Estratégico e na coordenação de equipes e compras compartilhadas, amparadas por critérios de sustentabilidade da padronização de bens e serviços. Os resultados demonstram que o modelo de governança proposto, participativo e construído coletivamente, favoreceu a criação de um clima de colaboração entre os diversos atores envolvidos no tema. 
Esta visão é reforçada por Cunha e Araújo (2019), que também observaram o envolvimento de vários atores (demandante, gestor, equipe de licitação, equipe de patrimônio e almoxarifado, consumidor final etc.), e enfatizaram que todos precisam ser capacitados e inseridos no processo. Neste sentido, uma das principais sugestões diz respeito à formação de uma Comissão de Sustentabilidade para verificar a inclusão dos critérios ambientais nos materiais que serão adquiridos. Como resultado, o estudo gerou uma nova postura dos requisitantes, que passaram a consultar alternativas mais sustentáveis para uma série de itens de materiais de consumo.

\section{Governança}

A governança e seus mecanismos são também motivos de pesquisas nacionais. A International Federation of Accountants (IFAC) (2013) entende que governança compreende a estrutura (administrativa, política, econômica, social, ambiental, legal e outras) posta em prática para garantir que os resultados pretendidos pelas partes interessadas sejam definidos e alcançados.

Um dos mecanismos desta estrutura é o leilão reverso, que efetua a seleção baseada no atributo preço, e se constitui base do Pregão Eletrônico do Portal Comprasnet. Segundo Menezes, Silva, e Linhares (2007), essa ferramenta possibilita a disputa por contratos mediante a submissão de lances decrescentes dos fornecedores, e tem alcançado resultados positivos em termos de agilidade, transparência e redução de custos, mas argumentam que a utilização de uma abordagem de decisão multicritério pode contribuir para um salto quali-quantitativo na execução das compras públicas brasileiras, proporcionando redução de custos e aumentando a qualidade dos bens e serviços adquiridos.

A utilização de sistemas gerenciais na administração pública brasileira também ocupa posição de destaque em pesquisas, tais como a de Cintra, Vieira, Barboza Júnior, Fernandes, e Baggio (2012) que estudaram o impacto da utilização de um Sistema de Informação Gerencial na gestão de contratos. Os autores apresentam a prevalência de resultados como qualidade e agilidade no trato com as atividades administrativas e eficiência na rotina dos contratos. Perceberam ainda que a instituição promoveu alterações, como a melhora do fluxo administrativo dos contratos, e treinamento de funcionários e gestores ligados a essa função, destacando o apoio e envolvimento da alta administração. Concluem registrando que a inclusão da tecnologia na gestão provocou mudanças significativas, como por exemplo, a redução de desperdício e tempo, melhora no controle de contratos.

Os sistemas de gestão e controle também têm estrita ligação com a eficiência e eficácia. Sobre o tema, Oliveira (2015) sugere melhorias nos trâmites, rotinas e controles processuais, aliadas à qualificação de atores envolvidos na elaboração de documentos que compõem a base do processo, trazendo como exemplo o Termo de Referência. Estes ajustes podem melhorar o nível de eficiência e impactar diretamente na eficácia percebida que seria a concepção do produto advindo da licitação. Tal relação com a eficiência de compras foi estudada por Tvaronavičienè, Žemaitaitienè, e Bilevičienė (2016) a partir de dados relativos a Lituânia, na qual os procedimentos eletrônicos de contratação pública podem ser efetuados pelo Sistema Central de Informações e se tornam uma medida que economizar dinheiro, recursos humanos e tempo para fornecedores e autoridades de compras.

Esta relação com a eficiência de compras também foi estudada por Tvaronavičienè et al. (2016) a partir de dados relativos a Lituânia, na qual os procedimentos eletrônicos de contratação pública podem ser efetuados pelo Sistema Central de Informações e se tornam uma medida que economizar dinheiro, recursos humanos e tempo para fornecedores e autoridades de compras. Kochanova, Hasnain, e Larson (2018) também analisam este uso da tecnologia aplicada às compras em diversos países e concluíram que o governo eletrônico reduz a corrupção e melhora a capacidade de gestão do governo, com efeito positivo nas compras.

Infelizmente, no Brasil esta discussão sobre gestão das compras, eficiência, eficácia e modelos gerenciais aplicáveis remonta a períodos históricos. Fernandes (2016) relata a trajetória de persistente debilidade institucional da área de compras e contratações públicas no Brasil. Segundo o autor, até 1930 a organização das compras se baseava na descentralização e autonomia dos órgãos. Todavia, a revolução impulsionou a formulação de uma política de centralização, apoiada na padronização dos bens consumidos pela administração pública e tendo como referência os casos dos Estados Unidos, Inglaterra, Alemanha, Canadá, Chile e Itália. Ao longo dos anos 1950 e 1960, os atos de governo enfraqueceram ainda mais o processo de centralização. Somente em 1990 teve início a estruturação atual, conformada a partir do desenvolvimento do sistema informatizado Siasg-Comprasnet, com importantes e surpreendentes impactos. Segundo o autor, a informática abriu caminho para a inovação nas regras e procedimentos, assim como, fortaleceu a organização sistêmica e o papel do órgão central, além de imprimir uma centralidade no âmbito dos serviços gerais que compõem o sistema. Entretanto, assevera que a pressão pública que buscou se proteger de agentes corruptos prejudicou economicamente as compras, pois o processo de centralização ficou relegado a segundo plano, e foi "desenhado" por meio de apêndices, como o decreto do pregão, do registro de preços e outros.

Como se pode observar, a discussão sobre a gestão das compras públicas é de extrema relevância, pois o serviço público por ela impulsionado é precursor fundamental da qualidade de vida, pode atuar para minimizar a pobreza e prestar serviços básicos para os cidadãos e não está restrita às fronteiras brasileiras. A falta de governança das compras relatada por Dzuke e Naude (2015) denota como a falta de governança e ineficiência do governo 
do Zimbábue contribuiu para deterioração dos serviços oferecidos à população. Os autores observaram que a estrutura legal das compras públicas no Zimbábue prejudica a prestação de serviços, pois são centralizadas em um Órgão Central que confere controle e autoridade excessiva aos gestores, impondo burocracia excessiva. Soma-se a tal condição a ineficiência e falta de transparência, fatores de risco que favorecem atos de corrupção Dzuke e Naude (2017).

A falta de governança também está presente no estudo de Šostar e Marukić (2017), que ao abordarem a Lei sobre contratos públicos da República da Croácia, relatam que os critérios para seleção de propostas em procedimentos de contratação pública têm como base a abordagem de custo-efetividade, mas que neste contexto foram identificados problemas significativos na área de planejamento e implementação da contratação, oriundos da preparação inadequada da documentação, e derivam de recursos humanos insuficientes ou sobrecarregados.

Já na seara da inovação de procedimentos organizacionais atinentes às compras, o panorama é bem distinto. Carneiro e Junior (2017) relatam um sistema Eletrônico de Compras que otimizou o processo e aumentou a eficácia na utilização dos recursos públicos diante do ganho de escala nas compras. O tema também foi objeto de estudo por Patrucco, Luzzini, Davide, e Ronchi (2019), que buscaram identificar a melhor estrutura conceitual de compras públicas em governos locais do País de Gales e na Itália. De acordo com os estudos, o nível de centralização e o status das compras dentro da instituição afetam os resultados, pois os autores descrevem que os aspectos governamentais e regulatórios influenciam as decisões, mas a organização das compras depende também de outros fatores internos e externos. Todavia, a oportunidade de aumentar a centralização das compras só parece possível se as escolhas de centralização forem motivadas por fatores governamentais de objetivos regulatórios ou de política institucional, com verdadeiro compromisso da gestão para promover esta mudança dentro da instituição.

Ocorre que estas melhorias só podem ser possíveis a partir de um planejamento robusto e compartilhado. Soares, Correia-Neto, Ribeiro, e Ferreira (2019) defendem que o formalismo exacerbado torna o processo de compras moroso, ineficaz e gera retrabalhos. Afirmam que quanto mais um servidor sabe sobre os principais elementos das tarefas que executa e sobre o domínio em que atua, melhor habilidade ele tem de planejar e executar suas atividades, por isso é necessária a constante capacitação e valorização dos atores destas funções.

Observando os riscos e desafios até agora relatados, podemos compreender melhor o estudo de Vieira, Macedo, e Hrdlicka (2019), que analisaram formas inovadoras de controle das compras governamentais com fulcro na garantia da efetividade do gasto público. A análise revelou falhas na contratação e execução em contratos de obras públicas devido ao projeto básico com número significativo de erros conceituais, fator de risco que pode gerar altos custos de repactuação, ou paralisar a obra. O uso de técnicas modernas consagradas no mercado, dentre elas a virtualização, modelagem e gerenciamento eletrônico da obra, hoje conhecido como BIM (Building Information Model - que em português pode ser traduzido para "Modelo de Informação da Construção), pode ajudar a mitigar estes riscos, mas o seguro, na modalidade performance bond, diminui suas consequências negativas ao garantir uma contrapartida monetária pelos dispêndios causados por estas incertezas, e consiste na transferência do risco para terceiros via contrapartida financeira.

De modo similar, ao analisar a literatura referente a compras públicas sob a perspectiva da avaliação de desempenho, G. B. P. d. Araújo e Sousa Lemos (2020) constataram: (i) a inexistência de autores renomados nessa área e de rede de colaboração; (ii) que os stakeholders são o foco que tem merecido atenção dos pesquisadores; (iii) que os modelos construídos não estão sendo capazes de oferecer subsídios à gestão de compras públicas; (iv) que o objetivo da AD tem sido avaliação, controle e motivação no âmbito das compras públicas; (v) destaque positivo para inexistência das falhas métricas de replicação de uma instituição para outra e foco excessivo em medidas financeiras; (vi) que, por outro lado, os modelos construídos para avaliar o desempenho não consideram os objetivos organizacionais e não fornecem informações aos gestores públicos; e (vii) forte preocupação com os stakeholders, tanto do contexto interno quanto do externo. Os autores observaram ainda compras repetidas, redundância de estruturas e procedimentos, desperdícios nos estoques, denotando mau uso dos recursos públicos e indicando um modelo de compras parcialmente centralizado, mas que possui características de descentralização. A solução para estes problemas pode residir na centralização das aquisições com a reforma e redefinição dos processos e procedimentos. Estes, por sua vez, devem estar embasados no uso de sistemas integrados para execução e gerenciamento do ciclo completo das compras, desde o planejamento, padronização dos procedimentos, levantamento da demanda, identificando o ponto de ressuprimento, acompanhamento contratual até a identificação dos resultados alcançados.

Outro ponto de análise dos estudos diz respeito aos aspectos legais das compras. Gaile, Tumalavičius, Skrastiņa, e Načiščionis (2020) relataram que investigar os objetivos da Lei dos Contratos Públicos da República da Letónia, observaram que tanto as entidades adjudicantes como as demais pessoas envolvidas no processo licitatório devem estar cientes da limitação da utilização do princípio da eficiência de gastos, pois focar apenas no aspecto legal pode levar a uma aquisição bem-sucedida, mas com baixa eficiência econômica. 


\section{CONCLUSÃO}

As compras públicas, segundo os resultados obtidos, mantêm estreita relação com as funções do Estado. Sua utilização nos últimos anos passou a ser observada pelo prisma da estratégia, perfazendo um novo instrumento para alçar as políticas públicas, sejam elas de cunho inovativo, social, econômico ou sustentável. Desta maneira, a governança dos desafios impostos para sua consecução é de primar a natureza para que esta possa cumprir com seu papel.

Vários são os atores envolvidos nos processos de compra e muitos são os riscos enfrentados; a ausência de competências e falta de capacitação tecnológica das empresas, somadas à inexistência de política formal de inovação e desorganização na oferta dos produtos pelo Estado impede a promoção das compras de cunho inovativo que podem incentivar o desenvolvimento local. Tal situação poderia ser contornada com a ampliação da procura do Estado por inovações, aliada a uma visão inovadora por parte do Governo e dos Compradores Públicos, que querem inovar, mas não sabem como. Alguns municípios já provaram que isso é possível promovendo o desenvolvimento local a partir de programas de compras públicas sustentáveis.

A sustentabilidade é tema atual e tem a simpatia dos pesquisadores da área, que demonstram o grande desafio para sua implantação. Compradores desqualificados, normas confusas, procedimentos morosos, falta de padronização, inadequação do mercado fornecedor, entre outros são fatores que ensejam os cuidados da gestão pública, e impactam diretamente na política sustentável. Se faz necessário que os Gestores Públicos capacitem seus compradores, e mais, que os motive a ser proativos neste processo, que diante do desafio, necessita de grande sinergia e coalizão para o sucesso.

Os estudos nos revelaram ainda que os processos de compras, por mais simples que possam parecer, são permeados por inúmeros fatores de risco, tal que afetam sua eficácia e se tornam desafios a serem transpostos. A Governança destes fatores é, de fato, objetivo necessário, pois somente com mecanismos fortes de gestão, aliados ao planejamento e controle, as variáveis negativas podem ser mitigadas e as positivas ampliadas.

Uma alternativa muito citada nos estudos diz respeito a centralização de compras, padronização de procedimentos, promoção de um ambiente colaborativo; tudo sob a premissa do planejamento em conjunto com a aplicação de modernos sistemas de informação. O Planejamento e a execução dos procedimentos de aquisição, com utilização de Inteligência Artificial e outros mecanismos que hoje podem ser observados no que se denomina "governo eletrônico" é uma realidade indissociável à nova Gestão Pública, pois alia procedimentos padronizados, ágeis e transparentes ao combate aos desperdícios, com economias significativas à medida que se pode centralizar e compartilhar as compras gerando ganhos de escala, e ainda é ferramenta poderosa para o controle e combate à corrupção.

Por fim, como sugestão de pauta para estudos futuros, observada a carência de estudos diretamente ligados ao tema, sugerimos abordar a análise e gestão dos riscos diretamente ligados às compras, de modo que tais fatores possam ser objeto de estudos aprofundados e não somente ser coadjuvante das pesquisas, como pudemos observar nesta RSL. A compra, em si, é um meio - e seus riscos carecem de estudos, mas sem ele não se pode atingir o fim que se pretende. 


\section{REFERÊNCIAS}

Araújo, G. B. P. d., \& Sousa Lemos, L. B. d. (2020). A Gestão de Compras Públicas: um Estudo de Caso da Central de Compras do Distrito Federal. Teoria e Prática em Administraç ao, 10(2), 124-137. doi: 10.21714/2238104X2020v10i2-51188

Araújo, G. C. d., \& Teixeira, C. E. (2018). Análise das compras públicas sustentáveis na Secretaria do Meio Ambiente do Estado de São Paulo. Gestão \& Regionalidade, 34 (100), 22-37. doi: 10.13037/gr.vol34n100.3744

Bardin, L. (2016). Análise de conteúdo. S ao Paulo: Ediç oes 70 .

Cabral, S., Reis, P. R. d. C., \& Sampaio, A. d. H. (2015). Determinantes da participação e sucesso das micro e pequenas empresas em compras públicas: uma análise empírica. Revista de Administração, 50(4), 477-491. doi: $10.5700 /$ rausp1214

Cader da Silva, R., Betiol, L., Villac, T., \& Nonato, R. (2018). Sustainable public procurement: the Federal Public Institution's shared system. Revista de Gestão, 25(1), 9-24. doi: 10.1108/REGE-11-2017-001

Caldas, E. d. L., \& Nonato, R. S. (2013). Compras públicas e promoção do desenvolvimento local. Revista do Serviço Público Brasília, 64(4), 465-480. Recuperado de http://www.spell.org.br/documentos/ver/35588/ compras-publicas-e-promocao-do-desenvolvimento-local

Camargos, N. M., \& Moreira, M. F. (2015). Procurement for Innovation in the Brazilian Ministry of Health: Present in the Discourse but Not in the Bidding Process. Contabilidade Gest ao e Governança, 18(3), 126-141. Recuperado de http://www.spell.org.br/documentos/ver/ 38300/compras-para-a-inovacao-no-ministerio-da-saude----no-discurso--sim--na-licitacao--nao

Carneiro, D. K. d. O., \& Junior, P. C. R. (2017, dez. ). Inovação no processo de compra de medicamentos: estudo de caso do ministério da saúde. Revista do Serviço Público, 68(4), 835-862. Recuperado de https://doi.org/10.21874/ rsp.v68i4.1618 doi: $10.21874 /$ rsp.v68i4.1618

Chaves, F. R. D., Bertassi, A. L., \& Silva, G. M. (2018, dez. ). Compras públicas e desenvolvimento local: Micro e pequenas empresas locais nas licitações de uma universidade pública mineira. REGEPE - Revista de Empreendedorismo e Gestão de Pequenas Empresas, 8(1), 77-101. Recuperado de https://doi.org/10.14211/regepe.v8i1.867 doi: 10.14211/regepe.v8i1.867

Cintra, R. F., Vieira, S. F. A., Barboza Júnior, D. C., Fernandes, C. R., \& Baggio, D. K. (2012). Impacto da implantaç ao de um sistema de informaç ao gerencial na gest ao de contratos públicos: o caso do Hospital Universitário de Dourados/MS. Revista de Administraç ao da UNIMEP, 10(2), 28-52. Recuperado de http://www.spell.org.br/documentos/ver/8227/ impacto-da-implantacao-de-um-sistema-de-informacao -gerencial-na-gestao-de-contratos-publicos $\backslash \mathrm{T} 1 \backslash$ textendasho -caso-do-hospital-universitario-de-dourados-ms

Cunha, S. F., \& Araújo, M. A. D. (2019, ago. ). Compras sustentáveis: Proposta de intervenção para as compras públicas do IFPB - campus campina grande. Revista de Gestão e Secretariado, 10(2), 112-139. Recuperado de https://doi.org/10.7769/gesec.v10i2.866 doi: 10.7769/gesec.v10i2.866

Denyer, D., \& Tranfield, D. (2009). Producing a systematic review. In D. A. Buchanan \& A. Bryman (Eds.), The Sage handbook of organizational research methods (p. 671-689). Leicester, UK: Sage Publications Ltd.

Dzuke, A., \& Naude, M. J. A. (2015, fev. ). Procurement challenges in the zimbabwean public sector: A preliminary study. Journal of Transport and Supply Chain Management, 9(1). Recuperado de https://doi.org/10.4102/jtscm.v9i1.166 doi: $10.4102 /$ jtscm.v9i1.166

Dzuke, A., \& Naude, M. J. A. (2017, fev. ). Problems affecting the operational procurement process: A study of the zimbabwean public sector. Journal of Transport and Supply Chain Management, 11. Recuperado de https://doi.org/ 10.4102/jtscm.v11i0.255 doi: 10.4102/jtscm.v11i0.255

Fernandes, C. C. C. (2016, set. ). A organização da área de compras e contratações públicas na administração pública federal brasileira: o elo frágil. Revista do Serviço Público, 67(3), 407-432. Recuperado de https://doi.org/10.21874/ rsp.v67i3.672 doi: 10.21874/rsp.v67i3.672

Ferreira Costa, C., Diniz, M. d. F. S., Cunha, N. R. d. S., \& Pires, R. R. (2016, dez. ). O fator sustentabilidade nas licitações e contratações públicas. REUNA, 21(4), 3756. Recuperado de https://doi.org/10.21714/2179-8834/ 2016v21n4p37-56 doi: 10.21714/2179-8834/2016v21n4p3756

Gaile, D., Tumalavičius, V., Skrastina, U., \& Načiščionis, J. (2020, set. ). Modern economics in the context of security: efficient use of funds and reduction of risks as one of the aims of public procurement. Entrepreneurship and Sustainability Issues, 8(1), 49-59. Recuperado de https://doi.org/10.9770/ jesi.2020.8.1(4) doi: 10.9770/jesi.2020.8.1(4)

Hall, R. J., de Moura, G. D., Macêdo, F. F. R. R., \& da Cunha, P. R. (2014). Compras públicas sustentáveis: um estudo nas universidades federais brasileiras. Amazônia, Organizações e Sustentabilidade, 3(1), 27-44. Recuperado de http://www.spell.org.br/documentos/ver/31485/ compras-publicas-sustentaveis $\backslash \mathrm{T} 1 \backslash$ textendashum-estudo -nas-universidades-federais-brasileiras

International Federation of Accountants (IFAC). (2013, jun). Governance in the Public Sector: A Governing Body Perspective. Consultation Draft for an International Framework.

Kochanova, A., Hasnain, Z., \& Larson, B. (2018, maio ). Does E-Government Improve Government Capacity? Evidence from Tax Compliance Costs, Tax Revenue, and Public Procurement Competitiveness. The World Bank Economic Review, 34(1), 101-120. Recuperado de https:// doi.org/10.1093/wber/lhx024 doi: 10.1093/wber/lhx024

Mendonça, R. A. M., Cruz, M. V. G. d., Teodosio, A. d. S. d. S., \& Raso, L. S. P. (2017, dez. ). Institucionalizaç ao de compras públicas sustentávies: Uma análise da experiência do Governo de Minas Gerais. REAd. Revista Eletrônica de Administração (Porto Alegre), 23(3), 62-91. Recuperado de https://doi.org/10.1590/1413-2311.161.61307 doi: 10.1590/1413-2311.161.61307

Menezes, R. d. A., Silva, R. B. d., \& Linhares, A. (2007). Leilões eletrônicos reversos multiatributo: uma abordagem de decisão multicritério aplicada às compras públicas brasileiras. Revista de Administração Contemporânea, 11, 11-33. Recuperado de http://www.spell.org.br/documentos/ ver/18031/leiloes-eletronicos-reversos-multiatributo $\backslash$ $\mathrm{T} 1 \backslash$ textendashuma-abordagem-de-decisao-multicriterio -aplicada-as-compras-publicas-brasileiras

Moreira, M. F., \& Vargas, E. R. (2015). Induç ao de Inovaç oes em Serviços: Compras Governamentais para a Inovaç ao ou Compras de Inovaç oes? Revista Gest ao \& Tecnologia, 15(2), 186-210. Recuperado 
de http://www.spell.org.br/documentos/ver/37368/ inducao-de-inovacoes-em-servicos $\backslash \mathrm{T} 1 \backslash$ textendashcompras -governamentais-para-a-inovacao-ou-compras-de-inovacoes $\mathrm{T} 1 \backslash$ textendash

Oliveira, I. G. S. (2015). Análise de correspondência aplicada a preposiç oes sobre a eficiência e eficácia do processo de compras públicas a partir da percepç ao de diferentes atores envolvidos. $R C A$ - Revista Ciências Administrativas, 21(1), 131-162. Recuperado de http://www.spell.org.br/documentos/ver/38362/ analise-de-correspondencia-aplicada-a-preposicoes-sobre -a-eficiencia-e-eficacia-do-processo-de-compras-publicas-a -partir-da-percepcao-de-diferentes-atores-envolvidos

Patrucco, A. S., Luzzini, H. W., Davide, \& Ronchi, S. (2019, jun. ). Which shape fits best? Designing the organizational form of local government procurement. Journal of Purchasing and Supply Management, 25(3), 100504. Recuperado de https://doi.org/10.1016/j.pursup.2018.06.003 doi: 10.1016/j.pursup.2018.06.003

Project Management Institute, Inc (PMI). (2017). Guia PMBOK®: Um Guia para o Conjunto de Conhecimentos em Gerenciamento de Projetos (6a. ed.). Pennsylvania: Project Management Institute, Inc.

Ribeiro, C. G., \& Furtado, A. T. (2015, set. ). A política de compras da Petrobras: o caso da P-51. Revista Brasileira de Inovação, 14(2), 289. Recuperado de https://doi.org/10 .20396/rbi.v14i2.8649109 doi: 10.20396/rbi.v14i2.8649109

Rocha, F. (2019, jun. ). Does public procurement for innovation increase innovative efforts? The case of Brazil. Revista Brasileira de Inovação, 18(1), 37-62. Recuperado de https://doi.org/10.20396/rbi.v18i1.8653575 doi: 10.20396/rbi.v18i1.8653575

Rosset, A. C. S., \& Finger, A. B. (2017, jan. ). Compras públicas sustentáveis: uma revisão sistemática da pesquisa brasileira. Revista de Administração, Contabilidade e Economia da Fundace, 7(3). Recuperado de https://doi.org/10.13059/racef.v7i3.412 doi: 10.13059/racef.v7i3.412

Silva, R. C., \& Barki, T. V. P. (2012). Compras públicas compartilhadas: a prática das licitaç oes sustentáveis. Revista do Serviço Público Brasília, 63(2), 157-175. Recuperado de http://www.spell.org.br/documentos/ver/ 35634/compras-publicas-compartilhadas $\backslash \mathrm{T} 1 \backslash$ textendasha -pratica-das-licitacoes-sustentaveis

Soares, A. R., Correia-Neto, J. d. S., Ribeiro, E. S., \& Ferreira, L. M. (2019). The purchases process and challenge in the planning stage: the case ofthe Universidade Federal Rural de Pernambuco. NAVUS-Revista de Gest ao em Tecnologia, 9(4), 264-273. doi: 10.22279/navus.2019.v9n4.p246273.958

Šostar, M., \& Marukić, A. (2017, dez. ). Challenges of public procurement in EU funded projects. Management: Journal of Contemporary Management Issues, 22(2), 99113. Recuperado de https://doi.org/10.30924/mjcmi/2017 .22.2.99 doi: $10.30924 / \mathrm{mjcmi} / 2017.22 .2 .99$

Sousa, E. d. S., \& Carvalho, D. B. d. (2018, jan. ). A função social das compras públicas pela inserção da variável ambiental: Caso de uma instituição federal de ensino superior. Gestão \& Planejamento, 19, 4-19. Recuperado de https://doi.org/10.21714/2178-8030gep.v19.3528 doi: 10.21714/2178-8030gep.v19.3528

Tvaronavičienè, A., Žemaitaitienè, G., \& Bilevičienè, T. (2016, set. ). Ecosystem for sustainable entrepreneurship: towards smart public procurement review procedures. En- trepreneurship and Sustainability Issues, 4(1), 39-52. Recuperado de https://doi.org/10.9770/jesi.2016.4.1(4) doi: 10.9770/jesi.2016.4.1(4)

Vieira, J. B., Macedo, R. G. d., \& Hrdlicka, H. A. (2019, nov. ). A relevância do seguro garantia nas compras públicas. Revista Brasileira de Políticas Públicas e Internacionais - RPPI, 4(2), 215-239. Recuperado de https:// doi.org/10.22478/ufpb.2525-5584.2019v4n2.46069 doi: $10.22478 /$ ufpb.2525-5584.2019v4n2.46069
Como citar este artigo (APA):

Sturmer, R. A., Garcia, E., Pereira, E. N. \& Peres, F. F. F. (2022). Compras públicas: uma revisão sistemática dos riscos e desafios. AtoZ: novas práticas em informação e conhecimento, 11, 1 - 11. Recuperado de: http://dx.doi.org/10.5380/atoz.v11.79840 


\section{FORMULÁRIO DE NOTAS DA OBRA E CONFORMIDADE COM A CIÊNCIA ABERTA}

\section{CONTRIBUIÇÃO DE AUTORIA}

\begin{tabular}{|l|c|c|c|c|}
\hline $\begin{array}{l}\text { Papéis } \\
\text { e contribuições }\end{array}$ & $\begin{array}{c}\text { Robinson } \\
\text { Alexander Sturmer }\end{array}$ & Elias Garcia & $\begin{array}{c}\text { Eliane Nascimento } \\
\text { Pereira }\end{array}$ & $\begin{array}{c}\text { Fabiana Frata } \\
\text { Furlan Peres }\end{array}$ \\
\hline Concepção do manuscrito & $\mathrm{X}$ & $\mathrm{X}$ & $\mathrm{X}$ & $\mathrm{X}$ \\
\hline Escrita do manuscrito & $\mathrm{X}$ & $\mathrm{X}$ & $\mathrm{X}$ & $\mathrm{X}$ \\
\hline Metodologia & $\mathrm{X}$ & $\mathrm{X}$ & $\mathrm{X}$ & $\mathrm{X}$ \\
\hline Curadoria dos dados & $\mathrm{X}$ & $\mathrm{X}$ & $\mathrm{X}$ & $\mathrm{X}$ \\
\hline Discussão dos resultados & $\mathrm{X}$ & $\mathrm{X}$ & $\mathrm{X}$ & $\mathrm{X}$ \\
\hline Análise dos dados & $\mathrm{X}$ & & \\
\hline
\end{tabular}

\section{CONFORMIDADE COM A CIÊNCIA ABERTA}

\section{Disponibilidade de Dados Científicos da Pesquisa}

Os conteúdos subjacentes ao texto da pesquisa estão contidos no manuscrito.

\section{EQUIPE EDITORIAL}

\section{Editora/Editor Chefe}

Maria do Carmo Duarte Freitas (https://orcid.org/0000-0002-7046-6020)

\section{Editora/Editor Adjunta/Adjunto}

Paula Carina de Araújo (https://orcid.org/0000-0003-4608-752X)

Editora/Editor de Texto Responsável

Cristiane Sinimbu Sanchez (https://orcid.org/0000-0002-0247-3579)

Nicholle Ferreira Murmel Liali (https://orcid.org/0000-0002-1086-908X)

Editora/Editor de Layout

André José Ribeiro Guimarães (https://orcid.org/0000-0003-0874-7400) 